\title{
POLÍTICA Y SUEÑOS COLECTIVOS: MIEMBROS DE LAS GENERACIONES DEL 70 Y DEL 90
}

\author{
Cecilia Millán La Rivera*
}

\begin{abstract}
RESUMEN
La historia reciente de Chile presenta importantes hitos que han configurado a nuestra sociedad, como fueron el período de la Unidad Popular y el retorno a la Democracia. Por lo mismo, en esta investigación interesa conocer las concepciones de política y los sueños que respecto a la sociedad actual tienen dos grupos que han vivido su juventud en cada uno de los períodos mencionados. Por una parte, jóvenes actuales estigmatizados como anómicos, distantes de la política y con motivaciones más difusas y, por otra, la juventud del período de la Unidad Popular, que se caracterizó por su rebeldía y la convicción real de poder cambiar el mundo. La metodología utilizada se basa en entrevistas semiestructuradas a ocho personas: cuatro corresponden a jóvenes en tiempos de la Unidad Popular y los otros cuatro a jóvenes del lapso del retorno a la Democracia. La conclusión a la que se arriba es que no existen diferencias importantes entre ambos grupos. El primero (jóvenes de los 70) ha modificado las concepciones de sociedad y política que sustentaban durante el período de la Unidad Popular y el segundo (jóvenes de los 90) refleja el discurso dominante en la actualidad. Con respecto a los sueños colectivos, prima en ambos la antiutopía.
\end{abstract}

PALABRAS CLAVE: JÓVENES, POLÍTICA, SUEÑOS, UNIDAD POPULAR, DEMOCRACIA

* Licenciada en Antropología, Magíster en Investigación Social y Desarrollo. Actualmente cursa el Doctorado en Ciencias Antropológicas en la Universidad Autónoma Metropolitana, México.

Correo electrónico: ceciliapazmlarivera@yahoo.com. 


\title{
POLÍTICA E SONHOS COLECTIVOS: MEMBROS DA GERAÇÃO DE 70 E DE 90
}

\begin{abstract}
RESUMO
A história recente do Chile possui marcos importantes para a configuração da nossa sociedade, como o período da Unidade Popular e o retorno à Democracia no Chile. $\mathrm{O}$ objetivo desta pesquisa é conhecer as concepções de política, bem como os sonhos sobre a sociedade atual de dois grupos que viveram sua juventude em cada um dos dois períodos mencionados. De um lado, os jovens da contemporaneidade, que têm sido estigmatizados como anômicos, distantes da política e com motivações mais difusas, e do outro lado, a juventude do período da Unidade Popular, que se caracterizou por sua rebeldia e a convicção real de poder mudar o mundo. Foram feitas entrevistas semi-estruturadas com oito pessoas, sendo quatro indivíduos do grupo de jovens da Unidade Popular e quatro jovens do período do retorno à Democracia. A conclusão é de que não existem diferenças significativas entre os dois grupos. $\mathrm{O}$ grupo de jovens dos anos 70 mudou as concepções de sociedade e política que tinha em sua juventude no período da Unidade Popular; o grupo de jovens dos anos 90 reflete o discurso dominante na atualidade. Sobre os sonhos coletivos, a anti-utopia prevalece em ambos os grupos.
\end{abstract}

PALAVRAS-CHAVE: JOVENS, POLÍTICA, SONHOS, UNIDADE POPULAR, DEMOCRACIA

\section{POLICY AND COLLECTIVE DREAMS: MEMBERS OF THE GENERATION OF THE 70'S AND 90'S}

\begin{abstract}
The recent history of Chile has important milestones that have shaped our society, as was the Popular Unity period and the return of Democracy in Chile. Thus, in this research it is of interest in knowing the views of policy, and the dreams youth have about today's society, two groups that have spent their youth in each of the periods mentioned. First, youth today who have been stigmatized as anomic, more distant from politics and motivations more diffuse and on the other hand the youth of the period of the Popular Unity, which was characterized by rebellion and real conviction to change the world. The methodology used is semi-structured interviews to eight people, four individuals who belong to these youth groups in the Popular Unity and four youths from the period of the return to Democracy. It concluded that there are important differences between both groups, modifying the youth group of 70 conceptions of society and politics that was about youth in the Popular Unity period and reflecting the youth group of 90 dominant discourse present. With regard to collective dreams in both groups we find anti-utopia.
\end{abstract}

KEY WORDS: YOUTH, POLITICS, DREAMS, POPULAR UNITY, DEMOCRACY 


\section{INTRODUCCIÓN}

EN EL ESCENARIO MUNDIAL, la política ha cambiado debido a diversos fenómenos como el colapso del comunismo o la globalización del mercado, lo cual se ha traducido en un malestar frente a la política (Lechner, 2005). En el caso de América Latina, se vive la paradoja de un alejamiento cada vez mayor de las personas de la política y, a su vez, de una legitimidad del sistema político democrático que se ha ido institucionalizando (Baquero, 2001). Chile también ha sido parte del proceso descrito, viviendo «un déficit de política en relación a la modernización económica» (Lechner, 1998:233). Si bien los motivos de tal situación varían y no todos los comparten - la dictadura militar, el modelo neoliberal imperante, la autodenominada «clase política» o la apatía de los individuos-, es claro que la política ha variado, según los individuos de nuestro país.

En el caso de Chile, el «déficit de política» responde a cambios externos, pero también a cambios políticos, económicos y sociales internos vividos durante los últimos cuarenta años, que han marcado e influenciado en las formas de relacionarnos y en las percepciones y valoraciones que hacemos de los distintos ámbitos de la realidad y del propio ser humano. Dicho período se caracterizó por tres grandes momentos: primer Gobierno Socialista elegido democráticamente, Golpe de Estado y, finalmente, retorno a la Democracia.

Durante tales etapas hemos transitado desde un Chile «sobre ideologizado», con fuertes compromisos políticos que despertaban pasiones y confrontaciones de ideas y proyectos de país (Zemelman, 2003; Arrate, 2003), a uno donde se cuestiona la política y no se defienden posturas frente al dilema de qué tipo de país se quiere construir (PNUD, 2004). Pasamos de ser un país con disidencias, a un país basado en una democracia del «consenso» (Astorga, Aravena y Gómez, 2006), de un país de sueños y esperanzas, a un país desesperanzado e inmediatista (Menéndez y Joignant, 1999).

Por esa razón, interesa conocer las concepciones de política y las posibles alternativas al tipo de sociedad actual que tienen estos dos grupos que han vivido su juventud en contextos tan diferentes a los nuestros: Unidad Popular y retorno a la Democracia. Para ello se optó teóricamente por el concepto de política planteado por el filósofo francés Jacques Rancière, en una búsqueda de nuevas concepciones que modifiquen las visiones tradicionales del concepto, que lo reducen a la administración del Estado o la relación de éste con la ciudadanía. 
Las nociones de política y policía establecidas por el pensador galo permiten dar cuenta de la dinámica de la sociedad y, a su vez, modificar la visión estática de política, fuertemente cuestionada por la ciudadanía. Con respecto a los sueños colectivos, se prefiere a Cornelius Castoriadis, Ernst Bloch y Esteban Krotz, quienes dan cuenta de la importancia de las utopías, develando, también, la existencia y el predominio actual de la antiutopía. Tales visiones permiten revisar, cuestionar, modificar y ampliar las posibilidades de cambio del orden existente, que se resiste a ser alterado porque predomina la idea de que no es posible cambiar a la sociedad.

\section{ANTECEDENTES TEÓRICOS}

\section{Generación y juventud: ¿diversidad o uniformidad?}

El concepto de generación suele utilizarse con criterios etarios; es decir, en función de las fechas de nacimiento de los individuos, lo cual supone que por el solo hecho de haber nacido en el mismo año un grupo pertenece a la misma generación (Ghiardo, 2004). Otro parámetro que se suma al mencionado son los contextos socioculturales: nacer en fechas cercanas supone compartir también contextos culturales y sociales semejantes, lo que hace que las personas participen de ciertos códigos y que se expresen en conductas similares, relacionándose la edad con comportamientos en común (Feixa, 1996).

El filósofo español Ortega y Gasset va más allá y considera que pese a las diferencias propias de toda generación, predominan ciertas características típicas que las distinguen de otras. Cree que existe un espíritu común y que cada generación tiene su propia vocación y misión histórica, más allá de las diferencias sociales e ideológicas existentes (Ortega y Gasset, 1981).

Por su parte, el sociólogo alemán Mannheim aporta al concepto de generación y señala que la edad no constituye un factor tan importante, considerando de mayor relevancia la situación de generación que vive un segmento de la población, lo cual une un tiempo histórico con condiciones sociales en común. De tal forma que las condiciones particulares de los sujetos determinarán subjetividades en común. Es así que una visión de mundo puede darse en función de situaciones particulares de clase, como el género o la generación. Mannheim llamará unidad generacional a la unión entre la edad y la experiencia similar. Así, dentro de una generación etaria podrían coexistir distintas 
generaciones. Pierre Bourdieu complementa lo planteado por este autor señalando que las generaciones no sólo se construyen en función de la edad, sino también de acuerdo a posiciones que se ocupan en el espacio y tiempo social en las relaciones sociales de una sociedad (Criado, 1998, en Ghiardo, 2004).

Por consiguiente, ambos grupos representan a dos generaciones distintas que se construyen en base al tiempo histórico particular en que nacieron, que los marca e impregna de una identidad generacional que los distingue unos de otros. Una generación tiene más recuerdos en común que los que existen con otras generaciones. Si bien una generación posee componentes unitarios dados por la edad y el contexto histórico, también contiene una diversidad de mundos que surge debido a las experiencias singulares que cada sujeto atesora, dependiendo de la posición que ocupe dentro de la sociedad.

A lo anterior se suman las distintas imágenes construidas socialmente en torno a la juventud, donde resulta imposible considerarlas todas. Por lo mismo, se han rescatado dos imágenes, las «más representativas» por lo visibles e institucionalizadas. Por una parte, jóvenes que creen que pueden cambiar el mundo y, por otro lado, quienes consideran que no es posible modificarlo.

Si tomamos la clasificación de Mariana Chaves (2005), caracterizaremos para la generación del 70 al joven como ser rebelde y/o revolucionario, ${ }^{1}$ y para la década del 90 al joven como ser desinteresado y/o sin deseo. ${ }^{2}$

\section{La política de «los sin parte» desde la mirada de Rancière}

El filósofo-político Jacques Rancière hace un aporte al ampliar la forma de abordar la política, sacudiendo el concepto de las clásicas definiciones que suelen reducirlo al ámbito estatal, con sus respectivas dimensiones y su relación con la ciudadanía. Desde la perspectiva de este autor, la política no se reduce a las decisiones que toma un Estado en función de las peticiones de servicios que solicita la población. Por el contrario, Rancière opta por profundizar y develar las dificultades existentes en las

1 Su naturaleza hace que sean jóvenes rebeldes y revolucionarios, lo que corresponde al papel designado: generar cambios sociales.

2 Este tipo de joven rechaza lo ofrecido por los padres, escuela y demás instituciones, siendo interpretados no por un desinterés en particular por lo que se ofrece, sino una apatía por todo. 
relaciones colectivas, reconociendo que el orden de toda sociedad implica acallar ciertos discursos y a algunos segmentos, y que sólo a partir de la visibilidad y subversión social se comienza a hacer política.

Rancière hace su propuesta a partir de un análisis crítico del de$m o s$ de la Grecia Antigua, sociedad que se funda en el principio de comunidad, donde todos los ciudadanos tienen un poder en común. Sin embargo, Aristóteles reconocía que tal comunidad estaba dividida por los oligoi, que son los ricos; los areté, que equivalen a los virtuosos, y la eleutheria, la libertad del pueblo (demos).

Tal división da cuenta de un principio de comunidad basado en una igualdad inexistente. Rancière lo denuncia y señala que lo que existe es una cuenta errónea o un desequilibrio secreto. En esa sociedad, el pueblo equivale a una masa indiferenciada que no posee título ni virtud; sólo se les reconoce la misma libertad que a aquellos que sí los poseen. Por tanto, el desequilibrio está en la idea de que el pueblo es como los oligarcas (oligoi) y los aristócratas (areté), siendo de que equivalen a los carentes de virtud y riqueza; es decir, las partes que no tienen parte (Rancière, 2006).

Por tanto, lo que existió en la sociedad griega y se mantiene hasta hoy es una distorsión, una contradicción entre dos mundos, entre quienes se ven y quienes no se ven, quienes tienen un logo (hablan verdaderamente) y aquellos cuya voz sólo imita la voz articulada. Por eso, lo político corresponde al conflicto acerca de la existencia de un escenario en común que no es tal, siendo su esencia el disenso que se da debido al conflicto entre dos mundos, entre las partes que no tienen parte y los que sí tienen parte (Rancière, 2006).

Tal conflicto de mundos se expresa en un orden que establece y decide por la comunidad, dividiéndola, por ejemplo, entre una clase política y la ciudadanía, entre expertos e ignorantes, elite y multitudes, jefes y subordinados, mayoría y minorías sociales, etcétera. Esa división da cuenta de lo político, de la existencia de una parte de la comunidad que no es verdaderamente parte de ella (Rancière, 2006).

La actividad política se daría cuando las partes que no tienen parte irrumpen en el orden de dominación, haciendo visible la desigualdad; o sea, en el momento en que el subordinado, la multitud, los ignorantes, etcétera, logran modificar su lugar en el espacio y transforman el ruido en discurso. Por tanto, la actividad política surge al evidenciarse la inequidad que quiere ser ocultada. Muestra de lo anterior es lo sucedido en 1849 en Francia, cuando Jeanne Deroin presentó su candidatura a la Asamblea legislativa, en circunstancias de que las 
mujeres no tenían derecho a votar ni a presentarse como candidatas, aun cuando el sufragio universal masculino había sido estipulado. «Ella muestra a sí misma y al sujeto «las mujeres» como necesariamente incluidos en el pueblo francés soberano que disfruta del sufragio universal y de la igualdad de todos ante la ley, y al mismo tiempo como radicalmente excluida» (Rancière: 1996:59). Esto es, a través de ese acto, ella devela lo ficticio de la igualdad de la comunidad, reordenando en el espacio el ser mujer.

Se suele señalar que la democracia busca el bien común, pero no sería tal. Más bien, lo que existiría son relaciones desiguales en las que hacen creer a una parte que sí son parte del todo; es decir, que son parte de la comunidad, lo cual es ficticio (Rancière, 1996).

La política surge cuando se evidencian los desequilibrios y se requiere armonizar las pérdidas y ganancias, acordándose la distribución en base al bien común, que se sustenta en el principio de igualdad. Sin embargo, como dice el autor, siempre termina siendo una falsa cuenta o una cuenta errónea. Hay «política cuando hay una parte de los que no tienen parte... cuando el orden natural de la dominación es interrumpido por la institución de una parte de los que no tienen parte» (Rancière, 1996:25). Por eso señala que el litigio integra la naturaleza de la política; fuera de eso, no existe política.

No obstante, la naturaleza de la política —el litigio- ha sido negada constantemente por los grupos de poder, quienes no han aceptado la existencia de la parte de los que no tienen parte. Y eso significa negar el litigio existente; negar la política. Tal litigio sería y es el escándalo de la política, el cual surge debido a las propias características humanas, que no tienen un orden dado por la naturaleza sino construido por el propio ser humano, quien organiza y ordena a la sociedad (Rancière, 1996). Aunque generalmente se suele entender por política los «procesos mediante los cuales se efectúan la agregación y el consentimiento de las colectividades, la organización de los poderes, la distribución de los lugares y funciones y los sistemas de legitimación de esta distribución», Rancière ha llamado a esto policía.

El concepto policía no se reduce a las fuerzas del orden ni al Estado, pero sí se vincula con ellos. Se refiere a un orden que establece y decide sobre la comunidad, «es, en su esencia, la ley, generalmente implícita, que define la parte o la ausencia de parte de las partes... define las divisiones entre los modos del hacer, los modos del ser y los modos del decir... es un orden de lo visible y lo decible que hace que tal actividad sea visible y que tal otra no lo sea, que tal palabra sea 
entendida como parte perteneciente al discurso y tal otra al ruido» (Rancière, 1996:44).

La policía se sustenta en la lógica de que existe un ejercicio de superioridad sobre una inferioridad, ejemplo de ello son la familia gobernada por el hombre o los ancianos, la empresa dirigida por los expertos, los estudiantes instruidos por los más sabios, etcétera (Rancière, 2006).

Este filósofo aclara que la política no es tal sólo por el hecho de que existan relaciones de poder, sino más bien porque ésta existe sólo en el encuentro de la lógica policial y la lógica igualitaria. Por lo tanto, una protesta o demanda de reforma llegará a ser política si se actúa o no sobre la policía. Por consiguiente, nada es política en sí mismo, ya que sólo existe por un principio que no le es propio: la igualdad; un supuesto que no es tal (Rancière, 1996).

La política se diferencia de la policía cuando «los cuerpos son desplazados de sus lugares naturales, los ruidos transformados en discursos y las acciones concentradas en reparar el daño, constitutivo a toda comunidad» (Olivos, 2002:194); constituye la transgresión a lo establecido en busca de la igualdad que existe por naturaleza entre los seres humanos, pero que se pierde precisamente por el orden humano llamado policía.

Por consiguiente, la política conlleva la subversión que significa exigir la igualdad que ha sido violada a través del orden policial. De tal manera, lo político se expresa en el choque entre dos lógicas distintas: la policía y la política. Y este choque presenta dos momentos: el primero, de resistencia frente a la policía, proceso que se caracteriza por desapropiarse de identificaciones establecidas que definen el ser, hacer y decir, y el segundo, de propuesta, es decir, plantear un nuevo orden, desconocido para la policía. Por lo tanto, lo político implica tanto resistencia como también subversión, se requiere modificar lo existente; de lo contrario, la resistencia sólo pasa a ser un ruido (Olivos, 2002).

\section{Libertad y creación}

La libertad y la posibilidad de autonomía y transformación de la sociedad se vinculan estrechamente con la capacidad de creación que tienen los seres humanos - cosa que de tan evidente se ha olvidado-, que ha posibilitado todo lo realizado hasta ahora y que hace posible pensar que pueda hacer y ser formas muy distintas a las existentes actualmente (Castoriadis, 1998). 
De esa manera, el ser humano se separa de la pura animalidad a partir de su capacidad de creación, expresada a lo largo de la historia humana y que no posee equivalentes presociales. Estas creaciones se manifiestan a través de la diversidad de sociedades existentes y de sus particularidades. Toda sociedad realiza constantes cambios, por muy mínimos que sean. Su máxima expresión es el lenguaje, que se ha constituido en parte de la naturaleza humana (Castoriadis, 2002).

El poder de creación llamado poiético da forma al caos, que no es otra cosa que la cultura. Esta creación se diferencia de la organización racional, que reproduce, repite y ordena lo ya existente. Castoriadis reconoce el poder de coerción de las sociedades, que lo ejercen para mantener sus propias instituciones y perpetuarse como tal, pero enfatiza la capacidad de creación del ser humano: una de sus características centrales, no así la racionalidad.

A esa capacidad de creación la llama imaginación e imaginario social. El primero se refiriere al individuo y el segundo, a la sociedad. $\mathrm{Y}$ son dos elementos fundamentales del ser humano (Castoriadis, 1998). Tal capacidad permite que existan sueños y esperanzas de construir una sociedad distinta a la existente.

La creación no sólo se verifica en la combinación de formas ya existentes, sino también en la producción de cosas nuevas mediante la expresión de imaginación radical. En este espacio se darían dos tipos de individuos: quien crea algo original y, por tanto, es capaz de una subjetividad critica, y el sujeto que recibe esta nueva creación y es capaz de recibirla o criticarla (Castoriadis, 1998).

Ambos individuos son creación socio-histórica y de las instituciones de su propia sociedad. Si bien existe una capacidad ilimitada de creación, no por ello estamos ajenos al medio en que nos insertamos. De hecho, no estamos determinados, pero sí condicionados (Castoriadis, 1998).

\section{Utopía: ¿un sí o no lugar?}

Frente a la insatisfacción de los seres humanos con su medio siempre han existido los deseos de cambio y mejora del actual estado de cosas, lo que en todas las sociedades humanas generan expectativas que se vinculan al ámbito de la utopía.

Este concepto no se entenderá como inalcanzable o fantasioso (Krotz, 1997) a pesar de su origen etimológico: deriva del griego topós (lugar) y el prefijo $u$ (no existe), lo que significa un lugar que no existe. 
A diferencia de la idea tradicional de utopía, el filósofo Ernst Bloch resignifica tal concepto, dinamizándolo. Todo acto de concreción exige un nivel previo de imaginación; por eso, lo que existe hoy no existía ayer, y sólo fue posible en la medida que se pensó. Por lo tanto, la utopía es lo que está por ser, por venir, algo nuevo (Gálvez, S/F).

Para Bloch, la utopía estaría presente en todas las sociedades humanas, ya que todas poseen capacidad de creación - concepto tan importante también para Castoriadis-, formando parte del desarrollo cultural de la humanidad, que se expresa a través de la literatura, en las palabras de Jesús, en el Marxismo, etcétera. A través de la religión también se plasma la utopía, proyectándose en ese Dios el anhelo de lo que desea alcanzar el ser humano en la Tierra (Celentano, 2005).

Es importante entender que la utopía nace de la insatisfacción frente a lo que existe, para lo cual el ser humano busca los mecanismos necesarios de cara a alcanzar sus deseos, trabajando para concretar dichos anhelos; de modo que el contenido de la función utópica es la esperanza, que nace del análisis de la realidad existente y sus alternativas de modificación. Tal situación genera un accionar no pasivo, sino activo del ser humano, por querer alcanzar la utopía, que es lo nuevo, lo que está por ser creado, combinándose condiciones objetivas que tienen que ver con la posibilidad y condiciones subjetivas que se refieren a la esperanza. Por lo tanto, la esperanza se une a las condiciones históricas de cada cultura (Celentano, 2005).

Lo importante de la utopía es la función que cumple, ya que permite pensar en mundos distintos, siempre mejores a los existentes. Bloch, al igual que Castoriadis, confía en la capacidad del ser humano para construir realidades distintas. Ese proceso de ser y de indicar un rumbo es lo que Bloch denomina utopía.

Frente a la crisis de las utopías, Esteban Krotz denomina antiutopía precisamente a esa forma de pensar que considera que no hay un futuro posible distinto al actual (Krotz, 1988). Si bien hoy se señala que las utopías están en crisis, lo importante radica en entender que el nudo no está en el éxito o el fracaso de las utopías, sino en la función que cumplen: expresar la inconformidad frente a lo existente y luchar por conseguir un futuro mejor, que debe ser construido.

\section{MÉTODO}

Para esta investigación se utilizó la entrevista individual semiestructurada y un muestreo intencional, que no busca una representatividad de 
la población sino comprender en profundidad los significados de dos grupos sobre la política y los sueños colectivos. El tipo de muestreo utilizado es el opinático, a través del cual se seleccionan a los sujetos de estudio en función de los objetivos de la investigación (Vieytes, 2004).

La muestra seleccionada abarca a ocho personas: cuatro individuos corresponden al grupo de jóvenes del 70 y cuatro al período de 1990. A continuación se exponen los criterios utilizados para la selección de cada uno, explicándose los motivos de tales criterios:

\begin{tabular}{|c|c|}
\hline GRUPO DE JÓVENES DEL 70 & GRUPO DE JÓVENES DEL 90 \\
\hline $\begin{array}{l}\text { 1. Período histórico: personas que } \\
\text { fueron jóvenes en torno al período de } \\
\text { la Unidad Popular (1968-1973), a los } \\
\text { cuales llamaré grupo de jóvenes del } \\
70 \text {. }\end{array}$ & $\begin{array}{l}\text { 1. Período histórico: personas que } \\
\text { fueron jóvenes durante el retorno a } \\
\text { la Democracia (1994-1999), a los } \\
\text { cuales llamaré grupo de jóvenes del } \\
90 \text {. }\end{array}$ \\
\hline $\begin{array}{l}\text { 2. Juventud: personas que hayan } \\
\text { tenido entre } 18 \text { y } 29 \text { años entre } 1968 \\
\text { y } 1973 \text {, que a la fecha tienen entre } 54 \\
\text { y } 70 \text { años. }\end{array}$ & $\begin{array}{l}\text { 2. Juventud: personas que hayan } \\
\text { tenido entre } 18 \text { y } 29 \text { años entre } \\
1994 \text { y } 1999 \text {, y que actualmente } \\
\text { tienen entre } 28 \text { y } 44 \text { años. }\end{array}$ \\
\hline $\begin{array}{l}\text { 3. Participación en partidos políticos: } \\
\text { personas que hayan militado en un } \\
\text { partido de izquierda durante el pe- } \\
\text { ríodo de la Unidad Popular; específi- } \\
\text { camente, un individuo por cada uno } \\
\text { de los siguientes: Partido Socialista } \\
\text { (PS), Partido Comunista (PC), Movi- } \\
\text { miento de Izquierda Revolucionaria } \\
\text { (MIR) e Izquierda Cristiana (IC). }\end{array}$ & $\begin{array}{l}\text { 3. Participación o no en grupos } \\
\text { organizados: personas que hayan } \\
\text { participando de alguna organiza- } \\
\text { ción entre la década de } 1994 \text { y } \\
\text { 1999, correspondientes a un club } \\
\text { deportivo y a un grupo religioso o } \\
\text { espiritual, y que no hayan integra- } \\
\text { do ninguna organización ni agru- } \\
\text { pación organizada. }\end{array}$ \\
\hline
\end{tabular}

Se seleccionaron dichos periodos históricos porque corresponden a etapas totalmente opuestas en términos ideológicos. El primero caracterizado por un intenso debate político y de polarización, de compromiso con lo social y el cambio, y un contexto internacional de tensas divisiones políticas, claramente definidas en dos posturas. El segundo, en cambio, se destaca por ser de mayor «homogeneidad política», con un predominio del consenso, menor apasionamiento con respecto a los temas sociales y un (aparente) desinterés por parte de la sociedad en la política y los cambios de la sociedad.

El criterio para definir juventud fue para ambos grupos la edad: entre 18 y 29 años. A pesar de que el INJUV (Instituto Nacional de la 
Juventud) establece que son jóvenes quienes tengan entre 15 y 29 años, se definió el rango anterior, ya que existen características totalmente distintas entre jóvenes de 15 a 18 años y de 19 a 29. Como señala Felipe Ghiardo (2004), los primeros están centrados en el estudio; en cambio, los otros se hallan preocupado de estudios de formación profesional o trabajando, lo cual da características bastantes disímiles a ambos segmentos.

Además del criterio etario se utiliza el de contexto socio-cultural; es decir, al nacer los sujetos en fechas similares se piensa que poseen aspectos culturales y sociales en común, que unifican ciertos códigos que se expresan en formas de pensar y conductas similares. Es necesario aclarar que esto se plantea en términos generales, ya que si bien hay códigos generacionales compartidos, también existen diferencias que dependen del lugar que se ocupe dentro de la sociedad. Por eso, el énfasis está más bien en las condiciones sociales en común, que influyen en las subjetividades de los sujetos: en el grupo de jóvenes del 70 por la militancia política en partidos de izquierda y en el grupo del 90 por la no participación en organizaciones de dos de los entrevistados y en la intervención en clubes deportivos y en la iglesia por parte de los otros dos, que se configuran en pieza de caracterización social de los jóvenes de ese período.

Por último, hay que señalar que si bien la militancia política unifica las subjetividades que se puedan tener frente a la visión de sociedad, tampoco con ello se asevera que todos los jóvenes militantes o los entrevistados hayan sido fieles representantes de un alto compromiso político con la revolución.

El tercer criterio utilizado fue el de militancia en partidos políticos de izquierda, siendo seleccionados los más representativos de ese período. Algunos integraban la coalición de la Unidad Popular como el PS, el PC y la IC. También se consideró al MIR, el cual, si bien estuvo al margen de la coalición mencionada, forma parte de los partidos políticos de izquierda. Las razones para elegir la militancia se debe a que asegura un compromiso político y social, que es lo que caracteriza a ese período histórico.

En cambio, con el segundo grupo los criterios son distintos, ya que la militancia política ha ido perdiendo peso, ${ }^{3}$ centrándose el eje en la participación o no en grupos organizados. Esta decisión se debe a

3 Según la $5^{\circ}$ Encuesta Nacional de Juventud, en 1998 la militancia de jóvenes entre 15 y 29 años equivale a $1,7 \%$. 
los datos recopilados por la Primera y Segunda Encuesta Nacional de Juventud aplicadas en los años 1994 y 1997, respectivamente, que representan a los jóvenes de la década de 1990. Ambas encuestas muestran que el porcentaje de no participación en grupos organizados equivale a $48,5 \%$ en 1994 y a $56,8 \%$ en 1997 . Por ello, se decide entrevistar cuatro personas: dos que no se hayan involucrado en ninguna organización durante su juventud y a otras dos que sí hayan participado en organizaciones. En este caso, se optó por las más representativas: clubes deportivos ${ }^{4}$ y organizaciones religiosas. ${ }^{5}$

A continuación presento un cuadro resumen de las principales características sociodemográficas de los entrevistados.

\begin{tabular}{|l|c|c|c|c|c|}
\hline \multicolumn{7}{|c|}{ GRUPO DE JÓVENES DEL 70 } \\
\hline Nombre & Edad & $\begin{array}{c}\text { Año de } \\
\text { nacimiento }\end{array}$ & $\begin{array}{c}\text { Nivel } \\
\text { educacional }\end{array}$ & Ocupación & Militancia \\
\hline Carmen & 60 & 1948 & $\begin{array}{c}\text { Cuarto } \\
\text { Medio }\end{array}$ & $\begin{array}{c}\text { Dueña } \\
\text { de casa }\end{array}$ & $\begin{array}{c}\text { Partido } \\
\text { Comunista }\end{array}$ \\
\hline Eduardo & 54 & 1954 & $\begin{array}{c}\text { Universitario } \\
\text { Incompleto }\end{array}$ & Comerciante & $\begin{array}{c}\text { Ex Movimien- } \\
\text { to de Izquierda } \\
\text { Revolucionaria }\end{array}$ \\
\hline Marcos & 60 & 1948 & Doctorado & $\begin{array}{c}\text { Profesor } \\
\text { universitario }\end{array}$ & $\begin{array}{c}\text { Ex Partido } \\
\text { Socialista }\end{array}$ \\
\hline Carlos & 78 & 1930 & Doctorado & Jubilado & $\begin{array}{c}\text { Izquierda } \\
\text { Cristiana }\end{array}$ \\
\hline
\end{tabular}

\begin{tabular}{|l|c|c|c|c|c|}
\hline \multicolumn{7}{|c|}{ GRUPO DE JÓVENES DEL 90 } \\
\hline Nombre & Edad & $\begin{array}{c}\text { Año de } \\
\text { nacimiento }\end{array}$ & $\begin{array}{c}\text { Nivel } \\
\text { educacional }\end{array}$ & Ocupación & Organización \\
\hline Andrea & 35 & 1974 & Magíster & $\begin{array}{c}\text { Profesora de } \\
\text { música }\end{array}$ & Religiosa \\
\hline Andrés & 34 & 1974 & $\begin{array}{c}\text { Cuarto } \\
\text { medio }\end{array}$ & $\begin{array}{c}\text { Auxiliar } \\
\text { instituto } \\
\text { educacional }\end{array}$ & Deportiva \\
\hline Evelyn & 32 & 1977 & Magíster & $\begin{array}{c}\text { Profesora de } \\
\text { castellano }\end{array}$ & Ninguna \\
\hline Miguel & 40 & 1968 & Universitario & $\begin{array}{c}\text { Contador } \\
\text { auditor }\end{array}$ & Ninguna \\
\hline
\end{tabular}

4 Con un porcentaje de participación en 1994 equivalente a $23,2 \%$, y en 1997 a $21 \%$.

5 Con un porcentaje de participación en 1994 de 12,1\%, y en 1997 de 15\%. 


\section{Resultados}

\section{Política: lógica policial frente a la lógica de igualdad}

La visión de ambos grupos sobre la política es muy similar, pues las dos se caracterizan por una concepción que incluye aspectos institucionales como el gobierno, partidos políticos, poder legislativo y ámbitos cotidianos de convivencia, mirada que amplía algunas nociones que se tienen de la política actual, que la reducen sólo a la esfera institucional.

También se concuerda en una visión de política más bien armónica, porque el conflicto sólo es considerado por dos personas representantes de los jóvenes del 70, quienes señalan que la política está condicionada por los grupos dominantes y por eso incluyen en ella la lucha y las protestas. Esta noción coincide con lo planteado por Rancière, quien da cuenta de que la lógica policial se impone sobre la lógica de igualdad, generando un litigio que da lugar a manifestaciones de resistencia como las protestas mencionadas.

Debido a los antecedentes ideológicos de la Unidad Popular y de la militancia política en un partido de izquierda se hubiese esperado por parte de todas las personas del grupo de jóvenes del 70 un énfasis en las relaciones de conflicto al interior de la sociedad, lo cual no sucedió. Tal situación puede ser explicada por el contexto histórico actual, que modifica el lenguaje omitiendo palabras como conflicto, lucha de clases sociales y hegemonía. Se valoran los consensos y se cuestiona la divergencia.

En el caso del grupo de jóvenes del 90, quienes no consideran los conflictos en la noción de política, sus respuestas son coherentes con lo que acontece en la realidad sociopolítica chilena. Una sociedad que desde el retorno a la democracia, en 1990, privilegió los consensos frente a las divergencias existentes y que considera la diferencia y el desacuerdo como algo negativo. Este grupo enfatiza la organización y administración de la sociedad, criterios fundantes de nuestro retorno y actual democracia, haciendo hincapié en que la política son los partidos políticos y el beneficio que debe dar el Estado a la ciudadanía.

Al ampliar el concepto de política preguntándoles por su visión de sociedad, igualdad y desacuerdos, encontramos dos visiones con respecto a la sociedad: una considera que ésta se basa en la cooperación y otra, en los conflictos.

Entre aquellos que consideran que la sociedad se basa en el conflicto, parte del grupo de jóvenes del 90 (Andrea y Evelyn) pone el 
acento en lo cotidiano y no en la dinámica interna de la sociedad, como señala Rancière; en cambio, aquellos que entienden el conflicto como parte de la estructura social integran el grupo de jóvenes del 70. Parte de este grupo (ex PS y ex MIR) señala que existe una lucha constante en que se impone un discurso dominante por sobre otro, siendo tal situación desconocida para la mayoría de las personas; es decir, sólo se percata de la lógica policial.

Con respecto a la igualdad, ambos grupos coinciden en que actualmente se viven relaciones desiguales, pero dan explicaciones distintas. El grupo de jóvenes del 70 y un entrevistado del grupo de jóvenes del 90 (Miguel) consideran la igualdad innata al ser humano, explicando las desigualdades existentes en razones sociales, como es la apropiación indebida de la riqueza y de los medios de producción. Argumentación muy coherente con el discurso de la Unidad Popular y con los conceptos marxistas utilizados en ese período. En cambio, los otros tres entrevistados de los jóvenes del 90 piensan que la igualdad no constituye una característica de los seres humanos, ya que la naturaleza humana es egoísta, por lo que la igualdad social resulta muy difícil, considerando «natural» las diferencias entre los seres humanos. Visión bastante pragmática y sin posibilidad de ser modificada.

Por tanto, ninguno explica la desigualdad como producto de una lógica desigual, que excluye de los espacios y de las decisiones de las formas de ser y hacer a un segmento de la población, haciendo creer que existe la igualdad.

Por último, con respecto a la noción de desacuerdo, hay diferencias tajantes entre unos y otros. El grupo de jóvenes del 70 utiliza un discurso similar al usado en su juventud, denunciando el orden imperante que legitima la desigualdad; es decir, el conflicto - parte de la concepción de política en la década del 70 - sólo emerge consensuadamente a partir de un concepto muy puntual: el desacuerdo. No sucede lo mismo con la noción de política, sociedad e igualdad, lo cual refleja que ha perdido peso en la visión de política. En cambio, el grupo de jóvenes del 90 califica los desacuerdos como mecanismos de enriquecimiento para la sociedad, en una apreciación totalmente opuesta al otro grupo.

Por consiguiente, la visión de política entre ambos grupos no resulta por entero discordante, ya que concuerdan en que abarca tanto los ámbitos institucionales cuanto los de la cotidianidad. Además, plantean un discurso que no cuestiona el orden imperante, ni el hecho de que éste impone una forma de vivir desigual, siendo considerado el 
conflicto sólo por dos personas del grupo de jóvenes del 70 (ex MIR y ex PS). Esta similitud hace pensar en que el contexto actual sí ha influido en las concepciones de la política y de la sociedad del grupo de jóvenes del 70 , porque prima una visión más consensuada, menos conflictiva y desigual. Por su parte, el grupo de jóvenes del 90 propone un discurso muy acorde con lo legitimado socialmente hoy.

Por consiguiente, no se puede afirmar que haya diferencias opuestas entre un grupo y otro respecto de estas materias.

\section{Política en la Unidad Popular y en la sociedad actual}

Respecto al período de la Unidad Popular, ambos grupos coinciden en señalar que fue una sociedad con esperanzas y sueños, con espacios nuevos de participación que incluyeron a segmentos que tradicionalmente habían sido excluidos. Asimismo, una sociedad de diferencias y conflictos sociales. Se considera que se buscó más igualdad a través de la redistribución económica y de la mayor participación política y que la sociedad mostró grados de resistencia contra la lógica policial que predominó en esa época.

Ambos grupos dan cuenta del litigio de esa época, expresado a través de la resistencia y subversión de las partes sin parte, que sintieron que atravesaban un momento histórico de protagonismo y de construcción de una sociedad distinta sin precedentes, frente al cual actuó la policía, dificultando tal transformación. Sólo Miguel, del grupo de jóvenes del 90, evalúa esa etapa como un momento de caos y de autoritarismo, valorando el actuar policial que imposibilitó que se llevase a cabo tal proyecto.

Por consiguiente, en este aspecto no hay diferencias importantes entre un grupo y otro; sólo Miguel no concuerda con la mayor participación ni con la apuesta de un proyecto de mayor igualdad. Es decir, la imagen de sociedad de la Unidad Popular con respecto a la política responde a lo que existe en la literatura sobre este tema, incluso la respuesta disidente de Miguel refleja las diferencias que se dieron en ese momento.

Por último, ambos grupos tienen una valoración positiva sobre este período, considerando que existen aspectos de esa sociedad que sería bueno rescatar; por ejemplo: la capacidad de soñar y de apasionarse en la vida.

A diferencia del concepto de política en la Unidad Popular, donde hay cierto grado de consenso entre ambos grupos, en el análisis de 
la sociedad actual existen grandes discrepancias entre ambos grupos. El de jóvenes del 70 considera que se vive en una sociedad policial, donde impera un orden que acentúa las desigualdades y que coarta la libertad y autonomía de los individuos. Son muy críticos de la política y de la presente sociedad, que se explica por sus ideas de juventud, época en la que creyeron en un cambio radical de la sociedad, con la creación de un hombre nuevo. También el haber vivido una época distinta les permite tener una visión diferente de organización de la sociedad y otro punto de referencia.

El grupo de jóvenes del 90, en cambio, valora de manera positiva a la sociedad y a la política, considerando que existe mayor igualdad, acceso a bienes, tolerancia y participación en las decisiones que se toman en el país, argumentando lo positivo de aquello, en contraposición a la desorganización que existió en la Unidad Popular.

Las divergencias pueden deberse a los contextos históricos de cada grupo. Uno vivió en una sociedad con predominio de lo político y otro, con un énfasis en lo policial. Es decir, la sociedad actual - policial—, avalada por el grupo de jóvenes del 90, puede ser explicada por el poder hegemónico del sistema policial que hace creer a la comunidad que lo existente es un espacio de convivencia igualitario, donde todos tienen similares oportunidades para acceder a los bienes y servicios deseados, y en el cual existe una verdadera participación en las decisiones importantes del país que afectan al conjunto, lo cual no es así.

Por tanto, el grupo de jóvenes del 70 tiene visiones de la política coincidentes para el período de la Unidad Popular y de la sociedad actual, pues en ambos momentos consideran que la sociedad y la política se basan en relaciones de desigualdad, existiendo un orden dominante que condiciona e invisibiliza las relaciones al interior de la sociedad; o sea, dan cuenta de lo que Rancière llama orden policial. Para este grupo, las diferencias entre una época y otra radican en que durante la Unidad Popular hubo un proyecto que quiso modificar tal orden policial, imponiéndose la política como la entiende Rancière: un momento caracterizado por intentar el reordenamiento del espacio de manera distinta, en el cual las partes que no tiene parte fueron protagonistas de lo que acontecía en el país. En cambio, en el período actual sólo predomina el orden policial, sin ese proyecto de política de la Unidad Popular, que buscaba la igualdad y modificar el orden presente.

Por otra parte, el grupo de los jóvenes del 90 no logra definir claramente la política y el tipo de sociedad en el período de la Unidad Popular, resultando vagas sus respuestas debido al desconocimiento de 
esa etapa de la historia. Eso refleja que sigue siendo un período histórico «tabú», del cual no se habla mucho. Ni siquiera los padres de los entrevistados conversan sobre esa época, a pesar de pertenecer a la generación que fue parte de ella. Pero, pese a lo poco que conocen de dicho lapso, los jóvenes consideran que fue una sociedad más participativa y de búsqueda de mayor igualdad.

Con respecto a la visión de política y de la sociedad actual, coinciden en que es una sociedad desarrollada con mayor igualdad y con mínimos desacuerdos y conflictos; vale decir, describen el orden policial, sin dar cuenta de la lógica de distorsión existente. Tal visión corresponde a lo que denuncia Rancière: cuando el orden policial nos hace creer en el principio de comunidad basado en una igualdad que no es tal.

En suma, sobre la visión de política de la Unidad Popular existe un consenso por ambos grupos. Se reconocen dificultades, pero se valora la lógica de igualdad que primó por sobre la policial, lo que se reflejó en la mayor inclusión de la población en las decisiones del país y en las mejores condiciones de vida. En cambio, la evaluación de la situación actual es totalmente opuesta entre un grupo y otro, siendo ponderada positivamente por el grupo de jóvenes del 90, en oposición al grupo de jóvenes del 70 .

\section{Sueños frente a la política actual y su viabilidad}

Con respecto a los sueños, ambos grupos manifiestan, con distintos énfasis e intereses, cambios en la sociedad, que se dividen en modificaciones estructurales y de convivencia. En el primer caso, se desea una sociedad con mayor igualdad, un vuelco económico y una sociedad más esperanzada; es decir, más utópica. En el segundo, una sociedad que recupere los valores familiares perdidos y que entregue mayor seguridad con respecto a las necesidades básicas.

Esto quiere decir que ambos grupos, a pesar de sustentar visiones distintas de la sociedad y de la política actual, coinciden en que se requieren cambios, concordando en la necesidad de una mayor igualdad. Este consenso confirma que la evaluación positiva realizada por el grupo de jóvenes del 90 sobre la sociedad actual y su igualdad obedece a la lógica policial existente, que hace creer que la sociedad avanza. Ello influye en la visión positiva que este grupo tiene de la sociedad, lo que no se condice con los deseos de cambio manifestados, que demuestran que hay aspectos que necesitan ser modificados. 
Los sueños de cambios estructurales de la sociedad no se manifiestan en todos los entrevistados del grupo de jóvenes del 70, sino que solamente en dos (ex PS y ex MIR), lo cual da cuenta de que una parte de ellos modificó el discurso de décadas pasadas. Esto puede ser explicado por la derrota vivida con el Golpe de Estado de 1973, que interrumpió el proyecto de la Unidad Popular, y a la opción de la Concertación, que ha continuado el modelo económico instaurado durante la dictadura. Por su parte, las respuestas del grupo de jóvenes del 90 que no incluyen cambios estructurales obedecen al contexto nacional, que acepta modificaciones de la organización de la sociedad siempre y cuando esté inserto en el actual modelo económico, no aceptando su cuestionamiento.

Con respecto a la forma de llevar a cabo los cambios mencionados, se constatan dos enfoques por parte del grupo de los jóvenes del 70. Por un lado, algunos siguen creyendo que las transformaciones deben ser rotundas y que sólo son posibles a través de la revolución, concordando con la postura de los «revolucionarios» en la Unidad Popular (ex MIR y ex PS). Por otro, algunos (PC y ex IC) señalan que los cambio deben ser paulatinos, lo cual puede ser expresión de un aprendizaje ocasionado por lo sucedido, habida consideración de que los grandes cambios deben ser acompañados de procesos sociales y sujetos que apoyen tales transformaciones, asegurando su viabilidad. El grupo de jóvenes del 90, por el contrario, opta por un cambio a través de caminos legales e institucionales acordes a los momentos vividos en nuestra sociedad, como la educación y políticos idóneos que representen los intereses de la población.

Por tanto, en las estrategias de cambio existen diferencias entre un grupo y otro. En el grupo de jóvenes del 70 se refleja en las experiencias y concepciones de política que se tuvo en la Unidad Popular, y en el grupo de jóvenes del 90 prima una visión de sociedad que apunta a cambios lentos y parciales.

Frente a quiénes deben llevar a cabo los cambios existen dos visiones que diferencian a ambos grupos. El grupo de jóvenes del 90 considera que es una responsabilidad de todos y que no existe vanguardia ni iluminados que puedan acometer las transformaciones de la sociedad. En cambio, el grupo de jóvenes del 70 estima que el rol de los dirigentes políticos sí es muy importante para que se genere un movimiento social de cambio, siendo fundamental el rol de los jóvenes. Tales visiones obedecen a las experiencias históricas de cada grupo. Una cree en el rol de los políticos o dirigentes para transformar 
la sociedad, además de que considera que en los jóvenes recae el deber de mejorar la sociedad. Otra no valora de manera positiva el rol del político, dándole mayor importancia a la sociedad en su conjunto, lo cual hace pensar que puede deberse al no cumplimiento de las expectativas por parte de los políticos.

Por último, respecto a la viabilidad no hay diferencias tan marcadas entre ambos grupos, primando la antiutopía. En ambos se da quienes creen posible modificar la sociedad y quienes lo consideran difícil. Los que encuentran poco viable cambiar la sociedad argumentan que el sistema es poderoso, resistiéndose a ser modificado. En el grupo de jóvenes del 90 mencionan cambios menores, lo que los hace factibles y más reales. El grupo de jóvenes del 70, por su parte, sigue juzgando posible transformar la sociedad a través de la revolución, lo cual da cuenta de una mayor capacidad de soñar que los que defienden el cambio del grupo de jóvenes del 90. En este último aspecto, se puede concluir que existe una diferencia generacional que revela que el grupo de jóvenes del 70 tiene mayor capacidad de soñar, ya que los tiempos de hoy no coinciden con revoluciones ni cambios radicales.

Por consiguiente, encontramos que todos cuestionan algún aspecto de la sociedad, requisito necesario para la utopía. Para que la utopía surja, primero se necesita reconocer la insatisfacción de lo existente; sin eso, no hay posibilidad de querer construir algo nuevo y distinto. Sin embargo, en la viabilidad de poder llevar a cabo tales cambios lo que prima es la antiutopía, considerando la mayoría que no resulta posible modificar las actuales condiciones. Sólo el entrevistado ex PS del grupo de jóvenes del 70 cree y quiere un cambio total de la sociedad, a diferencia de los que confían en el cambio, pero sus sueños aluden a pequeñas modificaciones totalmente viables de llevar a cabo.

\section{Conclusiones}

A partir de los relatos, se concluye que no existen diferencias entre ambos grupos con respecto a la visión de política y sociedad, predominando la distorsión señalada por Rancierè: un discurso dominante que hace creer en la armonía e igualdad de la sociedad y de la política, pero cuyos grupos de poder desconocen constantemente la esencia de la política: el litigio.

Por consiguiente, en este nivel de conceptualización es posible señalar que el grupo de los jóvenes del 70 ha modificado las concepciones de sociedad y política que sustentaban con respecto a su juven- 
tud en el período de la Unidad Popular y que, efectivamente, los cambios sociales y políticos han modificado el lenguaje de una generación que tuvo una visión de política y sociedad totalmente distinta a la actual; es decir, hay una ruptura por parte del orden dominante que logra instalar un discurso de valoración de lo existente a pesar de las desigualdades. En cambio, el grupo de jóvenes del 90 sólo ha reflejado el discurso dominante en la actualidad.

El grupo de la generación del 70, con respecto a la visión de política en la Unidad Popular, mantiene el discurso de esa época, explicitando el orden policial y las distorsiones existentes en la sociedad. Al compararse la política de la Unidad Popular con la época actual no se modifica el discurso en su esencia; sin embargo, el lenguaje se suavi$\mathrm{za}$, en concordancia con el discurso dominante.

Llama la atención la percepción en extremo positiva de la generación del 90, pues la mayoría de sus integrantes considera que vivimos en una sociedad de igualdad, a pesar de todas las deficiencias y desigualdades que persisten en términos económicos y sociales, con una sociedad que vulnera constantemente los derechos de los individuos de una u otra manera. ${ }^{6}$ Una sociedad de esa naturaleza y avalada por la juventud indica que el orden policial ha funcionado de manera exitosa.

Con respecto a los sueños colectivos, entre todos los entrevistados predomina la antiutopía. Si bien ambos grupos consideran necesario introducir cambios en nuestra sociedad -incluso señalando quiénes podrían ser los protagonistas y cuáles los medios-, indican que tales cambios no son viables.

Estas respuestas muestran lo que sucede con ambas generaciones: una «castración» de las utopías. Se instala el discurso de la antiutopía, lo que representa el mayor logro del orden policial, al cual no le interesa que el orden imperante sea modificado o, si es cambiado, que sea mejorando lo existente pero no cambiando el orden instaurado.

Finalmente, se concluye que sí existen diferencias generacionales en las apreciaciones de política y sociedad en los dos períodos históricos estudiados, pero no así en la visión de política y sociedad de forma a-histórica. Tampoco en los sueños colectivos, coincidiendo ambos grupos en un predominio de la antiutopía. El consenso en estas dos

6 En el texto «Habitar lo social» se da cuenta de una sociedad totalmente distinta a la que se menciona. Esta investigación cualitativa muestra que Chile es una sociedad con una profunda división moral, no siendo respetados los derechos de las personas. 
Política y sueños colectivos

últimas apreciaciones de la realidad refleja cómo las condiciones culturales, políticas y sociales moldean y modifican los discursos del grupo de jóvenes del 70, quienes en su juventud tuvieron discursos disímiles a los planteados actualmente, y cómo se reproducen los discursos hegemónicos por parte de ambos grupos, predominando el orden policial actual.

SANTIAGO (CHILE), MARZO 2010

RECIBIDO: MARZO 2010

ACEPTADO: JUNIO 2010

\section{REFERENCIAS BIBLIOGRÁFICAS}

Arrate, Jorge (2003): «Protagonistas y encrucijadas de la Unidad Popular». En R. BAÑo: Unidad Popular, 30 años después. Santiago: LOM.

Astorga, Freddy; Pedro Aravena y Rodrigo Mundana (2006): Los jóvenes, la política y el espacio público. Santiago: Escaparate.

CASTORIADIS, CORNELIUS (2002): Figuras de lo pensable (Las encrucijadas del laberinto VI). México: Fondo de Cultura Económica. (1998): El ascenso de la insignificancia. Madrid: Cátedra.

CELENTANO, ANDRÉS (2005): «Utopía, concepto y política». Revista Utopía y Praxis Latinoamericana, Vol.10, №31.

CHAVES, MARIANA (2005): «Juventud negada y negativizada: representaciones y formaciones discursivas vigentes en la Argentina contemporánea». Última Década $\mathrm{N}^{\circ} 23$. Valparaíso: Ediciones CIDPA.

FeIXA, CARLES (1996): «Antropología de las edades». En: PRAT y MARTÍNEZ: Ensayos de antropología cultural. Barcelona: Ariel.

GÁlVEZ, IsIDRO (S/F): «La función utópica en Ernst Bloch». Disponible en: www.posgrado.unam.mx.

GHIARDO, FELIPE (2004): «Generaciones y juventud: una relectura desde Mannheim y Ortega y Gasset». Última Década No20. Valparaíso: Ediciones CIDPA.

KATHYA, ARAUJO (2009): Habitar lo social. Usos y abusos en la vida cotidiana en el Chile actual. Santiago: OXFAM LOM.

KROTZ, ESTEBAN (1997): «La dimensión utópica en la cultura política: perspectivas antropológicas». En R. Winocour: Culturas polí- 
ticas a fin de siglo. México: Facultad Latinoamericana de Ciencias Sociales.

KROTZ, ESTEBAN (1988): «Invitación a la utopía: en torno a utopías y antiutopías». Revista Nueva Antropología, Vol. XI, No37.

LECHNER, NORBERT (2005): Los patios interiores de la democracia. Obras Escogidas 1. Santiago: LOM.

— (1998): «Modernización y democratización: un dilema del desarrollo chileno». Estudios Públicos Nº70, Santiago: CEP.

MANNHEIM, KARL (1987): Ideología y utopía. México: FCE.

MENÉNDEZ, AMPARO y ALFREDO JoIGNANT (1999): La caja de Pandora. El retorno de la transición chilena. Santiago: Planeta/Ariel.

OLIVOS, LEONARDO (2002): «Sujeto de la política, sujeto de la igualdad. A propósito de Rancière». Revista Mexicana de Ciencias Políticas y Sociales $\mathrm{N}^{\mathrm{o}} 184$.

ORTEGA y GASSET, JOSÉ (1981): La rebelión de las masas. Madrid: Espasa-Calpe.

RANCIÈRe, JACQUeS (2006): Política, policía, democracia. Santiago: LOM.

(1996): El desacuerdo. Buenos Aires: Ediciones Nueva Visión.

VIEYTES, RUT (2004): Metodología de la investigación en organizaciones, mercado y sociedad. Buenos Aires: Editorial de las Ciencias.

Zemelman, Hugo (2003): «La Unidad Popular como construcción de sociedad». En R. BAÑo: Unidad Popular, 30 años después. Santiago: LOM. 